\title{
Avaliação da contaminação por bromato em pães do tipo francês
}

\section{Analysis on the occurrence of bromate contamination in French type bread}

RIALA6/1610

\author{
Dayanna Joyce Marques QUEIROZ*, Everlane Ferreira MOURA, Manuela Alves da CUNHA ${ }^{1}$, Anna Cecília Queiroz de \\ Medeiros $^{2}$ \\ *Endereço para correspondência: ${ }^{1}$ Departamento de Nutrição, Centro Universitário do Rio Grande do Norte (UNIRN), Rua Prefeita \\ Eliane Barros, 2000, Tirol, CEP 59014-540, Natal, RN, Brasil. Tel.. (84) 32152917, 32152918. E-mail: dayannajoyse@hotmail.com \\ ${ }^{2}$ Departamento de Nutrição, Universidade Federal do Rio Grande do Norte, Natal, RN, Brasil \\ Agência financiadora: CNPQ \\ Número do processo: 139059/2010-5 \\ Recebido: 18.03.2014 - Aceito para publicação: 29.05.2014
}

\section{RESUMO}

O setor de panificação no Brasil tem realizado esforços para acompanhar as tendências de um mercado exigente e competitivo, e uma das alternativas tem sido os agentes oxidantes. O bromato de potássio $\left(\mathrm{KBrO}_{3}\right)$ é um agente oxidante que fortalece as cadeias de glúten. Apesar de benefícios tecnológicos e econômicos, sua toxicidade como aditivo alimentar tem sido demonstrada. No Brasil o emprego do $\mathrm{KBrO}_{3}$ é proibido em qualquer quantidade nas farinhas e nos produtos de panificação. Foram investigadas amostras de pão Francês provenientes de 25 pontos comerciais, que foram analisadas em triplicatas, totalizando-se 75 ensaios. A determinação de bromatos foi realizada em duas etapas: primeiramente pela prova de triagem utilizando-se o método analítico qualitativo, para identificar amostras positivas para agentes oxidantes e, posteriormente, a determinação de $\mathrm{BrO}_{3}^{-}$usando o reativo fucsina-bissulfito. Em todas as amostras foram detectados agentes oxidantes. $\mathrm{Na}$ análise confirmatória de bromato, foi identificada a presença deste aditivo em amostras de seis estabelecimentos dos 25 analisados, correspondendo à frequência de $24 \%$ nas amostras examinadas. Este estudo mostra que apesar da proibição do emprego de $\mathrm{KBrO}_{3}$ em produtos de panificação, há ainda o uso deste componente pelos estabelecimentos comerciais, e isto representa risco à saúde da população.

Palavras-chave. pão, aditivos alimentares, contaminantes químicos.

\begin{abstract}
Bread-making sector in Brazil has been doing efforts in order to follow the trends of a demanding and competitive market, and the use of additives (oxidizing agents) has been one alternative. Bromate potassium $\left(\mathrm{KBrO}_{3}\right)$ is an oxidizing agent that enhances the gluten chains. Despite their technological and economical benefits, the toxicity of this product has been demonstrated when used as a food additive. In Brazil the addition of $\mathrm{KBrO}_{3}$ in flour and bakery products is prohibited, in any amount. The French-type bread samples collected from 25 commercial spots were analyzed in triplicates, being in total 75 trials. The bromate detection was performed in two steps: firstly a screening test by using a qualitative analytical method for identifying the oxidizing agents-positive samples; and subsequently the determination of $\mathrm{BrO}_{3}$ using the fuchsin-bisulfite reagent. This component was found in all of the analyzed samples. The confirmatory analysis identified bromate occurrence in samples from six of 25 analyzed stores, corresponding to a frequency of $24 \%$ of analyzed samples. In spite of the use of potassium bromate has been forbidden in bakeries, this additive has still been employed by bread factories, representing a risk to the population health.
\end{abstract}

Keywords. bread, food additives, chemical contaminants. 


\section{INTRODUÇÃO}

O pão, um dos alimentos mais antigos da humanidade, também é um dos mais populares ainda hoje. Sua popularidade se deve ao excelente sabor, preço e fácil disponibilidade. $\mathrm{O}$ Brasil conheceu este alimento no século XIX tendo sua atividade de panificação expandida com a chegada dos imigrantes italianos. Sua produção é o resultado do cozimento de massa feita com farinha de trigo, água, sal e fermento (biológico ou químico), sendo estes os componentes básicos para a sua fabricação ${ }^{1}$.

É um alimento considerado popular, sendo consumido na forma de lanches ou com refeições, possuindo em sua composição a principal fonte energética do ser humano, o carboidrato, além de apresentar vitaminas do complexo B (tiamina-B1, riboflavina-B2, niacina e tocoferóis) e minerais, como ferro, potássio, sódio, cálcio, magnésio e fósforo ${ }^{2}$.

Porém, o pão é composto não só por componentes básicos e nutricionais, mas também por pequenas quantidades de aditivos alimentares para melhorar as características da massa durante o processamento e a qualidade comercial do produto final. Estes aditivos podem ser gorduras vegetais, açúcares, emulsificantes, agentes oxidantes e enzimas ${ }^{3}$.

Aditivos alimentares são utilizados para corrigir as deficiências da farinha de trigo, melhorar as características reológicas da massa, aumentar o volume do pão e prolongar a vida útil dos produtos obtidos, entretanto podem agir como agentes oxidantes, branqueadores, emulsificantes e conservantes ${ }^{4}$.

$\mathrm{O}$ bromato de potássio $\left(\mathrm{KBrO}_{3}\right)$ é um agente oxidante que tem como finalidade favorecer a maior retenção de gases (aumento do volume), umidade e melhor textura. Entretanto, através de estudos toxicológicos in vivo e in vitro, o comitê de peritos da $\mathrm{FAO} /$ OMS em Aditivos Alimentares considerou o bromato de potássio como sendo um carcinógeno genotóxico, além de a ingestão prolongada poder ocasionar vômitos, diarreia, possuir efeitos mutagênicos, destruir a vitamina B1, inibir a disponibilidade do ferro e degradar o ácido fólico, sendo, portanto, impróprio para uso como aditivo em farinhas e pães ${ }^{5}$.

Desta forma em muitas partes do mundo, o uso do bromato de potássio como melhorador de pão foi proibido. No Brasil, sua utilização foi proibida a partir da lei $\mathrm{n}^{\circ} 10.273 / 2001^{6}$ em qualquer quantidade nas farinhas, no preparo de massas e nos produtos de panificação. No entanto, na literatura encontram-se registros que provam o uso do bromato ilegalmente para o crescimento de pães adulterados, por padarias pouco e sem nenhuma fiscalização nas grandes cidades do país ${ }^{5,7}$.

Diante do exposto, o presente estudo torna-se relevante tendo em vista a importância para a saúde da população e os escassos estudos no Brasil após a proibição da sua utilização na indústria de panificação. Desta forma, a presente pesquisa teve por objetivo investigar a presença de bromatos em pães do tipo francês de diversos estabelecimentos nas quatro regiões da cidade do Natal-RN.

\section{MATERIAL E MÉTODOS}

\section{Tipo de estudo, local de realização e procedimentos gerais}

Realizou-se pesquisa laboratorial com abordagem qualitativa em amostras de pães do tipo francês, comercializados em diferentes regiões da cidade de Natal-RN, para avaliar a presença de bromato.

A amostragem compreendeu padarias, mercadinhos e supermercados, localizados em quatro regiões de Natal, de forma não probabilística. As análises foram realizadas no Laboratório de Bromatologia do Centro Universitário do Rio Grande do Norte (UNIRN).

\section{Obtenção e preparação das amostras}

Foram coletadas oito amostras de pães do tipo francês em cada um dos 25 pontos comerciais da cidade de Natal/RN e distribuídos pelas quatro regiões da cidade, (norte, sul leste e oeste) sendo 17 padarias, três mercadinhos e cinco supermercados. Todas as amostras foram adquiridas na qualidade de consumidor.

As amostras foram encaminhadas ao Laboratório de Bromatologia do UNIRN em embalagem original e foram mantidas em temperatura ambiente e protegidas de umidade. Ao início de cada experimento, as amostras foram submetidas a secagem em estufa a $105^{\circ} \mathrm{C}$ por 24 horas, trituradas em um multiprocessador de alimentos (modelo RI 7762 Philips Wallita) e pesadas em triplicata, totalizando 75 ensaios. As amostras foram preparadas de acordo com o tipo de análise ao qual seriam submetidas: (i) identificação qualitativa de agentes oxidantes e (ii) identificação qualitativa de bromatos. 


\section{Prova de triagem para a presença de agentes oxidantes}

A pesquisa de agentes oxidantes foi realizada com base na metodologia descrita pelo Instituto Adolfo Lutz - IAL8.

Após a trituração, com um auxílio de uma peneira de malha fina, $10 \mathrm{~g}$ das amostras foram distribuídas sobre um papel filtro, sobre as quais foi adicionada solução de iodeto, sendo o aparecimento de pontos violetas indicativo da presença de agentes oxidantes8. As amostras que apresentaram $c$ reação positiva foram submetidas à investigação comprobatória de $\mathrm{BrO} 3$ -

\section{Prova confirmatória de bromatos}

Nas amostras positivas para agentes oxidantes, foi realizada a confirmação da presença do bromato com o método indireto com o reativo fucsina-bissulfito, conforme descrito pelo Instituto Adolfo Lutz ${ }^{8}$.

Cada amostra com aproximadamente $50 \mathrm{~g}$ foi incinerada em mufla a $550{ }^{\circ} \mathrm{C}$ por $2-4$ horas até a obtenção de resíduo com cor cinza claro, transferido para dessecador até resfriar, por 30 minutos e posterior identificação do brometo formado pela decomposição térmica do bromato. Foi utilizado sistema de dissolução para isolar o brometo em cada amostra, através da mistura das cinzas com o ácido sulfúrico a $10 \% \mathrm{~m} / \mathrm{v}$, seguida da adição de água oxigenada a $30 \% \mathrm{~m} / \mathrm{v}$ e acrescentados 3 $\mathrm{mL}$ do reativo fucsina-bissulfito previamente preparado (dissolução de $0,1 \mathrm{~g}$ de fucsina em pequenas porções de água, triturando-a com bastão de vidro, até atingir 100 $\mathrm{mL}$. Adicionando, com agitação, o bissulfito de sódio em pó até descorar totalmente a solução). O aparecimento de coloração lilás persistente é um indicativo da presença de brometos. Esse método indica qualitativamente a presença de bromatos presente no alimento.

\section{Analise estatística dos dados}

Os dados foram analisados por software estatístico SPSS (Statistical Package for the Social Sciences). Os dados foram submetidos à análise descritiva e para investigar a dependência entre as variáveis, foi feito o teste exato de Fisher, com nível de significância de 5 \%.

\section{RESULTADO E DISCUSSÃO}

Os resultados das análises indicaram a presença de agentes oxidantes em todas as amostras conforme previsto, considerando que na formulação da massa do pão geralmente são usados aditivos oxidantes, estes agem nas proteínas do glúten formando ligações dissulfeto e conferem fortalecimento à massa. Os agentes oxidantes, como ácido ascórbico, azodicarbonamida e bromato de potássio são os mais comumente usados no setor de panificação, entretanto, o bromato de potássio tem seu uso proibido pela legislação brasileira9 .

Indrani e $\mathrm{Rao}^{10}$ avaliaram o efeito de agentes oxidantes, agentes redutores e enzimas na massa de farinha de trigo e observaram que o bromato de potássio e o ácido ascórbico promoveram aumento da estabilidade da massa e área extensográfica, sendo este um dos fatores que levam as panificadoras a fazerem uso dos agentes oxidantes.

A partir dos resultados encontrados dos agentes oxidantes foi realizada a investigação comprobatória do bromato, indicando a presença de $\mathrm{BrO}_{3}^{-}$em pães do tipo francês coletados em seis estabelecimentos dos 25 analisados, distribuídos pelas zonas norte, sul, leste e oeste da cidade do Natal/RN, correspondendo a uma freqüência de $24 \%$ nas amostras analisadas (Figura 1), sendo que as zonas que apresentaram maiores índices de contaminação por $\mathrm{BrO}_{3}$ - foram as norte e leste.

Os resultados obtidos confirmam os índices encontrados na literatura sobre o uso indevido desse agente oxidante, proibido pela legislação ${ }^{6}$. Machado e Reyes ${ }^{11}$ identificaram a presença de bromato de potássio em nove das 18 amostras de marcas de melhoradores líquidos provenientes da região nordeste, enquanto Albino et $\mathrm{al}^{12}$, quando analisaram amostras de pães em 29 estabelecimentos, detectaram a presença do bromato de potássio em amostras de seis deles.

Oloyede e Sunmonu ${ }^{13}$ demonstraram que a ingestão de pães contendo bromato de potássio por camundongos ocasionou graves efeitos sobre o fígado e células renais, evidenciado por atividades reduzidas de alanina transaminase (AST), aspartato transaminase (ALT) e fosfatase alcalina (ALP) nos tecidos. O consumo de tais pães pode resultar em danos nos rins e no fígado e, como tal, devem ser evitados.

Na Figura 2, observa-se o resultado da análise qualitativa confirmatória para bromato em pães do tipo francês de acordo com o tipo de estabelecimento pesquisado, na qual é evidenciada que a contaminação por bromato ocorre apenas em padarias e mercadinhos, o que pode ser explicado pelo maior rigor na fiscalização a que estão submetidas as grandes empresas. Estes dados corroboram o estudo de Rafael et $\mathrm{al}^{14}$, que destacou que embora alguns países já tenham proibido o uso de 
Queiroz DJM, Moura EF, Cunha MA, Medeiros ACQ. Avaliação da contaminação por bromato em pães do tipo francês. Rev Inst Adolfo Lutz. São Paulo, 2014; 73(2):233-7.

bromato de potássio na produção do pão, este ainda continua a ser utilizado principalmente por padarias que comercializam produtos artesanais.

Emeje et $\mathrm{al}^{5}$ mostraram que, na análise qualitativa de 23 amostras de pães analisadas, 21 delas apresentaram a cor lilás indicativa da presença de bromato, enquanto que na análise quantitativa foi percebida a presença do aditivo em $100 \%$ das amostras. O estudo justificou este resultado estabelecendo a possibilidade de que possivelmente as amostras de pães que não foram identificadas na análise qualitativa devido à presença de quantidade residual insuficiente na amostra que não poderia ser detectados pelo reagente.

Porém, no presente estudo não houve relação estatisticamente significativa entre a positividade para brometo e a zona da cidade e/ou o tipo de estabelecimento $(\mathrm{p}>0,05)$.

\section{CONCLUSÃO}

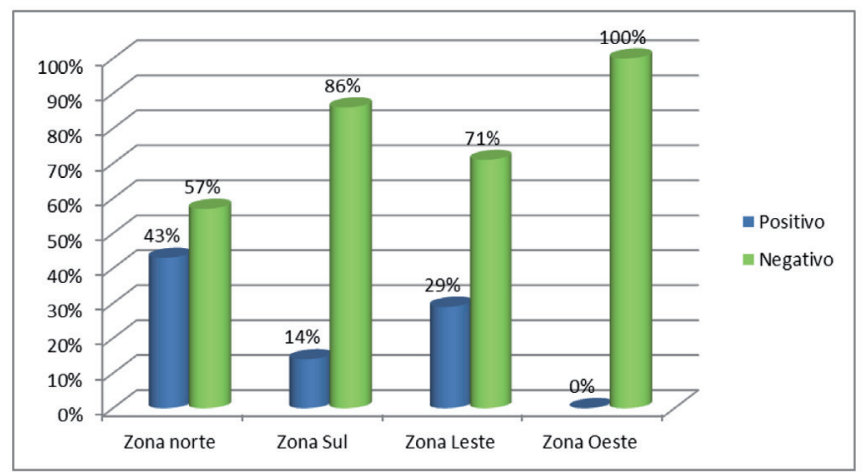

Fonte: Dados da Pesquisa (2011)

Figura 1. Percentagem de amostras de pão francês contaminadas por bromatos por zonas da cidade do Natal/RN em 2011

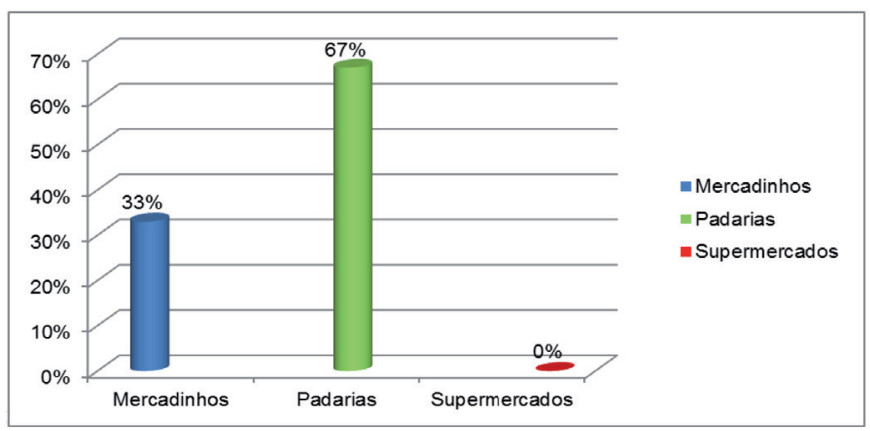

Fonte: Dados da Pesquisa (2011)

Figura 2. Percentagem de amostras de pão do tipo francês contaminadas por bromatos por tipo de estabelecimentos da cidade do Natal/RN em 2011
Todas as amostras de pães do tipo francês analisadas indicaram a presença de agente oxidante, sendo que $24 \%$ apresentaram bromato, principalmente na região da zona norte de Natal/RN. Este fato é preocupante, tendo em vista que não é permitida qualquer quantidade deste aditivo em produtos de panificação, devido o grau de toxicidade e carcinogenicidade, além de perdas nutricionais. Os resultados obtidos sugerem a necessidade de intensificar a fiscalização junto aos proprietários dos estabelecimentos, através de orientações sobre os riscos do uso do bromato de potássio, além do desenvolvimento de mais estudos com análises qualitativas e quantitativas nos pães e produtos de panificação a fim de identificar este aditivo mesmo que em pequenas quantidades.

\section{REFERÊNCIAS}

1. Sebrae. Encarte Técnico: A importância do Pão do Dia (Tipo Francês) para o segmento da Panificação no Brasil.[ acesso em: 15 Julho. 2011 ] Disponível em: [http://www.biblioteca.sebrae. com.br/bds/bds.nsf/d086c43daf01071b03256ebe004897a0/4c9f e331fb9d9a73832576ac00662e6a?OpenDocument]

2. Araújo WMC, Montebello NP, Botelho RBA, Borgo L . Alquimia dos Alimentos. Brasília: Editora SENAC-DF; 2009.

3. Polônio MLT, Peres F. Consumo de aditivos alimentares à saúde: desafios para a saúde pública brasileira. Cad-Saúde Pública. 2009; 25(8): 1653-66.

4. Pavanelli AP. Aditivos para panificação: conceitos e funcionalidade. Oxiteno S/A Indústria e Comércio, São Paulo, 2000. [acesso em: 2 jul. 2010] Disponível em: http://www. oxiteno.com.br/aplicacoes/mercados/doc/documento

5. Emeje MO, Ofoefule SI, Nnaji AC, Ofoefule AU, Brow SA. .Assessment of bread satety in Nigeria: quantitative determination of potassium bromate and lead. Afr J Food Sci.2014;(6):394- 97-

6. Brasil. Lei ${ }^{\circ}$. 10.273, de 05 de setembro de 2001. Dispõe sobre o uso do bromato de potássio na farinha e nos produtos de panificação. Diário Oficial [da] União. Brasília, DF, 06 de Set. 2001. [acesso em: 5 de Maio de 2010]. Disponível em: http:// www.lexml.gov.br/urn/urn:lex:br:federal:lei:2001-09-05;10273.

7. Dallago RM, Nascimento Filho L, Zanella R, Maroneze AM. Determinação de bromato em melhoradores de farinha por cromatografia de troca iônica com detecção espectrofotométrica. Quim Nova.2005;28(4):716-8.

8. Zenebon O, Pascuet NS, Tiglea P. Métodos físicos e químicos de análise de alimentos. $4^{\text {a }}$ ed. São Paulo: Instituto Adolfo Lutz; 2008.

9. Pereira EPR, Amorim EOC, Ambiel HCI, Chang YK. Influência de agentes oxidantes sobre as propriedades reológicas de massas de farinha de trigo branca sobre o volume específico de pão francês. Braz J Food Technol.2009;12(3):161-171.

10. Indrandi D, Rao GV. Effect of additives on rheological characteristics and quality of wheat hour parotta. J Tex Stud.2006;37(3):315-38. 
11. Machado MCMST, Reyes FGR. Determinação de bromato de potássio em farinhas. Rev Farm Bioquím Univ SP.1995;31(1):29-33.

12. Albino E, Souza RCR, Gomes SC, Santos AC, Beltrão AB. Bromato de potássio em aditivos para a panificação usada em padarias do III Distrito Sanitário do Recife, PE-2006. Hig Alim.2009;23(170/171):151-5

13. Oloyede OB, Sunmonu TO. Potassium bromate content of bread samples selected in Ilorin, Nigeria Central and their effect on some enzymes of the liver and rat kidney. Food Chem Toxicol.2009;47(8):2067-70.
14. Rafael A, Pino J, Gonzales J, Francia JC, Shiga B. Efecto citoprotector del camu-camu Myrciaria dúbia en tres líneas celulares de ratón expuestos in vivo a bromato de potássio. Rev Peru Biol.2010;17(3):389- 92. 